\title{
Cumulative versus transient shoreline change: Dependencies on temporal and spatial scale
}

\author{
Eli Lazarus, ${ }^{1}$ Andrew Ashton, ${ }^{2}$ A. Brad Murray, ${ }^{3}$ Sarah Tebbens, ${ }^{4}$ \\ and Stephen Burroughs ${ }^{5}$
}

Received 27 July 2010; revised 24 February 2011; accepted 8 March 2011; published 21 May 2011.

[1] Using shoreline change measurements of two oceanside reaches of the North Carolina Outer Banks, USA, we explore an existing premise that shoreline change on a sandy coast is a self-affine signal, wherein patterns of change are scale invariant. Wavelet analysis confirms that the mean variance (spectral power) of shoreline change can be approximated by a power law at alongshore scales from tens of meters up to $\sim 4-8 \mathrm{~km}$. However, the possibility of a power law relationship does not necessarily reveal a unifying, scale-free, dominant process, and deviations from power law scaling at scales of kilometers to tens of kilometers may suggest further insights into shoreline change processes. Specifically, the maximum of the variance in shoreline change and the scale at which that maximum occurs both increase when shoreline change is measured over longer time scales. This suggests a temporal control on the magnitude of change possible at a given spatial scale and, by extension, that aggregation of shoreline change over time is an important component of large-scale shifts in shoreline position. We also find a consistent difference in variance magnitude between the two survey reaches at large spatial scales, which may be related to differences in oceanographic forcing conditions or may involve hydrodynamic interactions with nearshore geologic bathymetric structures. Overall, the findings suggest that shoreline change at small spatial scales (less than kilometers) does not represent a peak in the shoreline change signal and that change at larger spatial scales dominates the signal, emphasizing the need for studies that target long-term, large-scale shoreline change.

Citation: Lazarus, E., A. Ashton, A. B. Murray, S. Tebbens, and S. Burroughs (2011), Cumulative versus transient shoreline change: Dependencies on temporal and spatial scale, J. Geophys. Res., 116, F02014, doi:10.1029/2010JF001835.

\section{Introduction}

[2] Quantifying the scales at which varying magnitudes of shoreline change occurs is an essential step toward understanding the physical causes of those changes. Such knowledge also can inform forecasts and models of long-term landscape change, which have economic importance wherever human infrastructure exists on dynamic coasts. Remotesensing technologies now enable researchers to resolve patterns of shoreline erosion and accretion across unprecedented ranges of scale. Previously, Tebbens et al. [2002] suggested that shoreline change, measured for tens of kilo-

\footnotetext{
${ }^{1}$ Senator George J. Mitchell Center for Environmental and Watershed Research, University of Maine, Orono, Maine, USA.

${ }^{2}$ Department of Geology and Geophysics, Woods Hole Oceanographic Institution, Woods Hole, Massachusetts, USA.

${ }^{3}$ Division of Earth and Ocean Sciences, Nicholas School of the Environment, Center for Nonlinear and Complex Systems, Duke University, Durham, North Carolina, USA.

${ }^{4}$ Department of Physics, Wright State University, Dayton, Ohio, USA.

${ }^{5}$ Department of Physics, University of Tampa, Tampa, Florida, USA.

Copyright 2011 by the American Geophysical Union. 0148-0227/11/2010JF001835
}

meters alongshore, follows a power law; the scaling exponent, a measure of the fractal roughness of the shoreline change pattern, is different between different reaches of shoreline. A comparison of lidar-derived shoreline changes over 1 year revealed a log-log linear relationship between alongshore scale and the variance of shoreline change that holds for alongshore scales spanning 1 order of magnitude, from approximately $10^{2}-10^{3} \mathrm{~m}$. Because continuous sandy coastlines typically exhibit plan view morphological undulations that extend up to several kilometers alongshore, we are motivated to investigate whether those apparent power law results remain robust at larger spatial scales $\left(>10^{3} \mathrm{~m}\right)$ and over longer temporal scales ( $>1$ year).

[3] Power laws are ubiquitous in quantitative analyses of natural and human processes, and describe the scaling structure of a great variety of phenomena. Typically, the presence of a power law is interpreted to imply that, because a quantity varies consistently between scales across a wide domain, a single principal process is operating over that domain. In many cases, the occurrence of power laws and self-similar patterns in nature likely does reflect the scaleinvariant dominance of one type of interaction [e.g., Bak, 1996; Murray, 2007]. Scale invariance in earthquakes, for 
example, is thought to indicate that the dynamics of small slip events are fundamentally similar to those of large ones, with each event changing the stress fields that affect other events at slightly different scales in a manner that does not depend on absolute scale [e.g., Bak et al., 2002]. In fluvial drainage basins, the magnitude and frequency of branched stream channels in a tributary network can be described by a power law, for which the physical process of sediment transport controls the spatial distribution of channel branching [Pelletier, 1999]. The avulsions of fluvial channels [Jerolmack and Paola, 2007] and avalanches in anisotropic granular material [Frette et al., 1996] are other examples of scale invariance in physical systems.

[4] In coastal landscapes, power laws have been applied to describe the fractality of shoreline geography [Mandelbrot, 1967], to investigate the frequency of plan view crescentic patterns [Dolan and Ferm, 1968], and to broadly classify dynamic shoreline features linked across a continuum of spatial and temporal scales [e.g., Cowell and Thom, 1994; Southgate and Möller, 2000; List et al., 2006; Gunawardena et al., 2008].

[5] However, in contrast to examples of scale-invariant behavior associated with a dominant interaction operating across the scales, a wealth of coastal morphodynamic studies have demonstrated that different physical processes affect a sandy shoreline at different spatial scales. At scales on the order of $10^{1} \mathrm{~m}$, swash zone feedbacks can give rise to patterns of beach cusps [Werner and Fink, 1993; Coco et al., 2003]; surf zone currents interacting with and reorganizing sandbars can affect beach changes on the order of $10^{2} \mathrm{~m}$ alongshore [Ruessink et al., 2007]; wave propagation over larger-scale complex nearshore bathymetric features, such as persistent shore-oblique bar fields, has been associated with shoreline change on the order of $10^{3} \mathrm{~m}[$ McNinch, 2004; Schupp et al., 2006]; and recent work suggests that large-scale shoreline curvature on the order of $10^{4} \mathrm{~m}$ may drive gradients in wave-forced alongshore sediment transport that affect large-scale shoreline change [Ashton et al., 2001; Ashton and Murray, 2006a, 2006b; Lazarus and Murray, 2007; List and Ashton, 2007]. A unifying, mechanistic explanation for consistent morphological relationships across a wide range of scales is therefore unclear, and the typical implications of a power law may not apply [e.g., Murray, 2007; Solow, 2005].

[6] Here, we demonstrate that shoreline change exhibits power law-like behavior across many scales at which disparate coastal evolution processes operate, prompting new questions with broad applicability: If a power law describes system behavior over a certain range of spatial scales, and yet distinct processes and interactions operate at different scales within that range, what causes the power law? Is this a stochastic accident? Could the spatial scaling relationship also be affected by temporal scale, such that time exerts some intrinsic control on the systemic behavior? Additionally, where does the scaling relationship appear to break down, and what process or linked processes dominate the system at that scale?

[7] Although power law behaviors are certainly interesting in and of themselves, the relationship we find between short-term and long-term patterns of change, over different spatial scales, carries perhaps the most significant implications: Our analysis shows that shoreline change variance at larger spatial scales is orders of magnitude greater than the variance registered at small scales, and that the spatial scale of the maximum in large-scale shoreline change variance tends to increase with time (for timescales $>1$ year). This suggests that the processes of long-term shoreline change that operate over large spatial scales are principally responsible for the greatest amounts of shoreline change, a result that bears on which scales of measurement are physically relevant in cases where cumulative, long-term changes are the record of interest.

\section{Methods}

\subsection{Shoreline Data}

[8] High-resolution digital elevation models (DEMs) converted from airborne lidar surveys of the North Carolina Outer Banks collected in 1996, 1997, 2005, and 2008 allow spatially rectified, quantitative measurements of shoreline change. We examine two continuous reaches of the North Carolina coast: $80 \mathrm{~km}$ of the Northern Outer Banks (NOBX), from the Virginia state line to north of Oregon Inlet, and $50 \mathrm{~km}$ of Pea Island (PI), from south of Oregon Inlet to north of Cape Hatteras (Figure 1). The study areas are free of hardened structures such as groynes or seawalls. We crop the surveys at least $5 \mathrm{~km}$ short of inlets and capes to minimize their effects on the shoreline change signal [Fenster and Dolan, 1996; Lazarus and Murray, 2007].

[9] Representative shorelines are extracted from the lidar surveys by converting raw Cartesian point clouds to $5 \mathrm{~m}$ gridded DEMs, registered to the 1988 North American Vertical Datum and projected to the UTM NAD83 Zone $18 \mathrm{~N}$ ellipsoid. Five meter gridding allows a conservative but consistent comparison between early lidar surveys and later data collections, which used different lasers that sampled at $\sim 5 \mathrm{~m}$ and $\sim 1 \mathrm{~m}$ spot sizes, respectively [Coastal Services Center, 2010]. Allowing for possible aliasing from alongshore features $<\sim 10-15 \mathrm{~m}$, we set the lower bound for our spatial analyses at $20 \mathrm{~m}$. From the DEMs, typically accurate to $\sim 10-40 \mathrm{~cm}$ in airborne lidar measurements, we sample the $1 \mathrm{~m}$ topographic contour, which preserves small-scale features in the beach, such as cusps, but is at an elevation high enough to minimize lidar data artifacts of wave interference [Lazarus and Murray, 2007]. The $1 \mathrm{~m}$ contour is within $0.5 \mathrm{~m}$ of the mean high-water line for the Outer Banks north of Cape Hatteras and is consistent with shoreline elevation proxies used in other lidar-based studies of the region [Tebbens et al., 2002]. (All data sets were downloaded from the NOAA Coastal Services Center's Digital Coast portal: www.csc.noaa.gov.) The 1997 lidar survey we use is a reprocessed version of the publicly available 1997 survey also used by Tebbens et al. [2002]. End point shoreline change is the difference between the $1 \mathrm{~m}$ shoreline positions surveyed on any two dates.

[10] Local beach slope can affect plan view shoreline positions derived from topographic contours, an inherent drawback to end point comparisons. Small volumetric changes to the beach where beach slope is relatively low can manifest as large linear differences in shoreline position; two adjacent reaches of beach with similar volumetric losses would show a greater change in shoreline position in the reach with the lower slope [e.g., List et al., 2006]. Previous work in this 


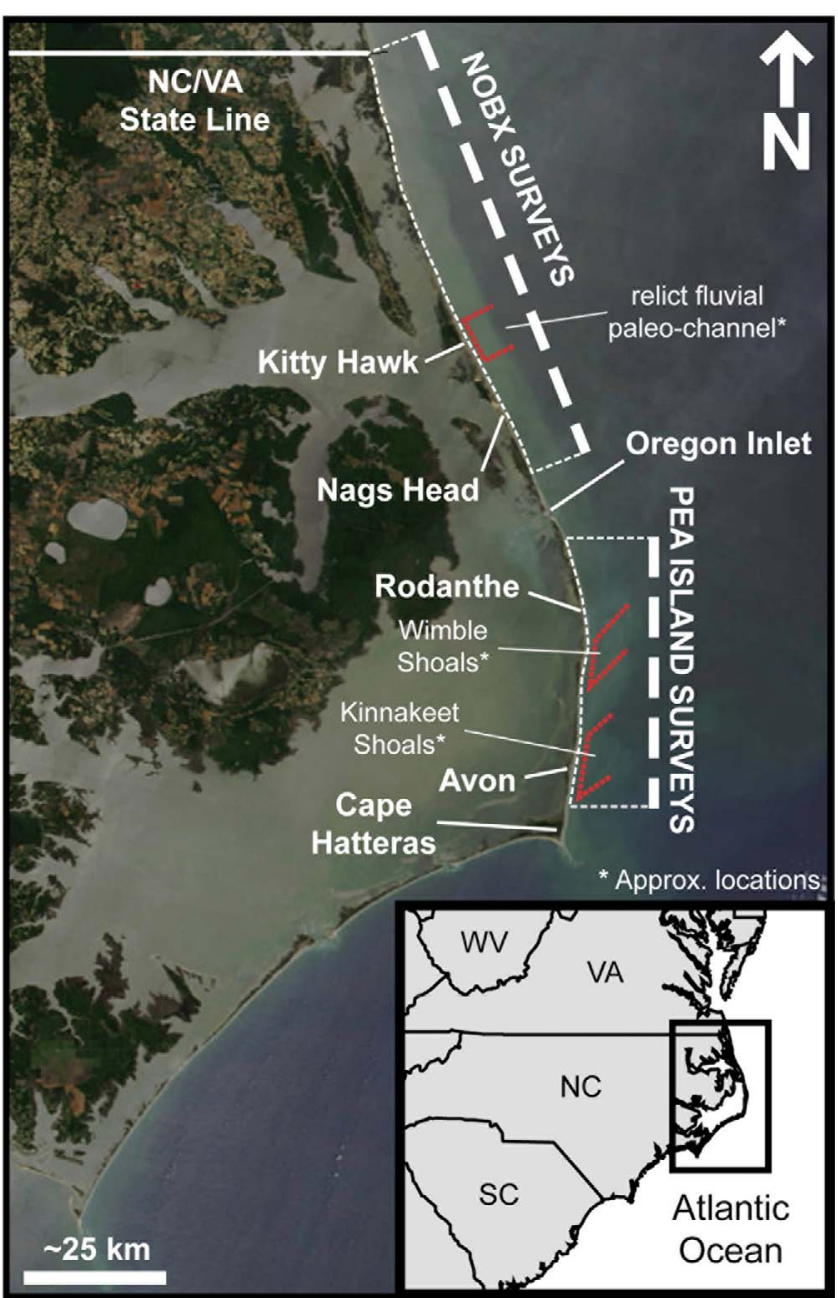

Figure 1. Map of the study area. Lidar surveys from 1996, 1997, 2005, and 2008 record shoreline change along the northern Outer Banks (NOBX) and Pea Island (PI). Approximate spans of localized geologic and bathymetric features are denoted in red. (Paleochannel location after McNinch [2004]; shoal locations after Riggs et al. [1995]; base image courtesy of NASA Visible Earth, http://veimages. gsfc.nasa.gov).

region found no discernable correlative relationship between alongshore variations in shoreline change and beach slope [List et al., 2003, 2006]. If beach slope affected shoreline change measurements, this influence would be expected to manifest at alongshore scales $<\sim 1000 \mathrm{~m}$, where beach slope is typically most heterogeneous [e.g., Madsen and Plant, 2001]. For the sake of general comparison, we checked our calculations of shoreline position change against an independent, multiyear data set of shoreline position change measurements extracted from a ground-based, buggy-mounted GPS system [List et al., 2006] and found strong alignment between the two data sets, reinforcing our choice of the $1 \mathrm{~m}$ contour as a sufficiently representative definition of the shoreline in this study.

\subsection{Wavelet Analysis}

[11] Using the differenced shoreline positions, we quantify shoreline change variability using wavelets, which are scaled filter transforms that, when convolved with a signal, return coefficients constituting a spatially localized measure of signal variability at a given scale. For basic explanations of wavelets and their history, properties, and applications, we recommend Hubbard [1996] and Nievergelt [1999].

[12] We perform wavelet analyses using the Wavelet Toolbox in Matlab R2009b, convolving shoreline change measurements with a Haar wavelet, or first-order Daubechies (" $d b 1$ "), in a continuous wavelet transform. There are many wavelet types, and deciding which wavelet to use typically depends upon the type of data under scrutiny and the goal of the analysis. One characteristic of a wavelet's shape is its number of vanishing moments: Generally, the more vanishing moments a wavelet has, the more its shape undulates, and the more sensitive it is to signal variability at fine scales [Hubbard, 1996]. A Haar wavelet is discontinuous, with such a simple shape that it has only one vanishing moment, making it less sensitive to variability at fine scales but appropriate for detecting patterns at lower frequencies. It is therefore particularly applicable to densely sampled, spatially extensive shoreline data such as ours. We experimented with several different wavelets, including $d b 2$, Morlet, and Meyer wavelets; all results were qualitatively similar, but the Haar's minimal vanishing moment offered better sensitivity over the greatest range of scales, particularly scales $>10^{3} \mathrm{~m}$.

[13] Concomitant with choosing a wavelet is whether to employ a continuous or discrete transform. Discrete transforms are nonredundant; the wavelet steps along the input signal like compass calipers. Continuous transforms are highly redundant because the waveform slides point-to-point along the entire signal at each scale of decomposition. We employ a continuous transform because redundancy can help illuminate patterns in the data that discretization can miss [Hubbard, 1996], and because computational processing capacity is not a limiting factor.

[14] Squaring the wavelet transform coefficients produces a measure of signal variance; averaging over the length of the signal then returns the mean shoreline variance at each wavelet scale, the equivalent of the power spectrum of a Fourier transform. (Unlike a Fourier transform, the waveletderived variance at each scale does not depend on phase coherence between undulations in different parts of the data set.) The utility of wavelet transforms is their preservation of spatial heterogeneities within a data series. Producing a power spectrum with a single mean value of variance at each spatial scale excludes valuable information about localized variations embedded in the data. However, a power spectrum provides a useful summary of how variance depends on scale, which complements the information about spatial heterogeneities in variance at particular scales.

[15] To mitigate edge effects in the coefficients at the beginning and end of a data series, we reflect the shoreline change signal several times, working with a multiple [e.g., Nievergelt, 1999]. Reflecting the signal introduces a small amount of artificial variance where the signal reverses. Without signal extension (or a comparable method of signal padding), variance in the wavelet transform is artificially suppressed at both ends of the initial signal by the wavelet's inherent shape, an edge effect termed the "cone of influence" (COI), which increases with wavelet scale [Ruessink et al., 2007]. Because we (1) use a continuous wavelet transform, 

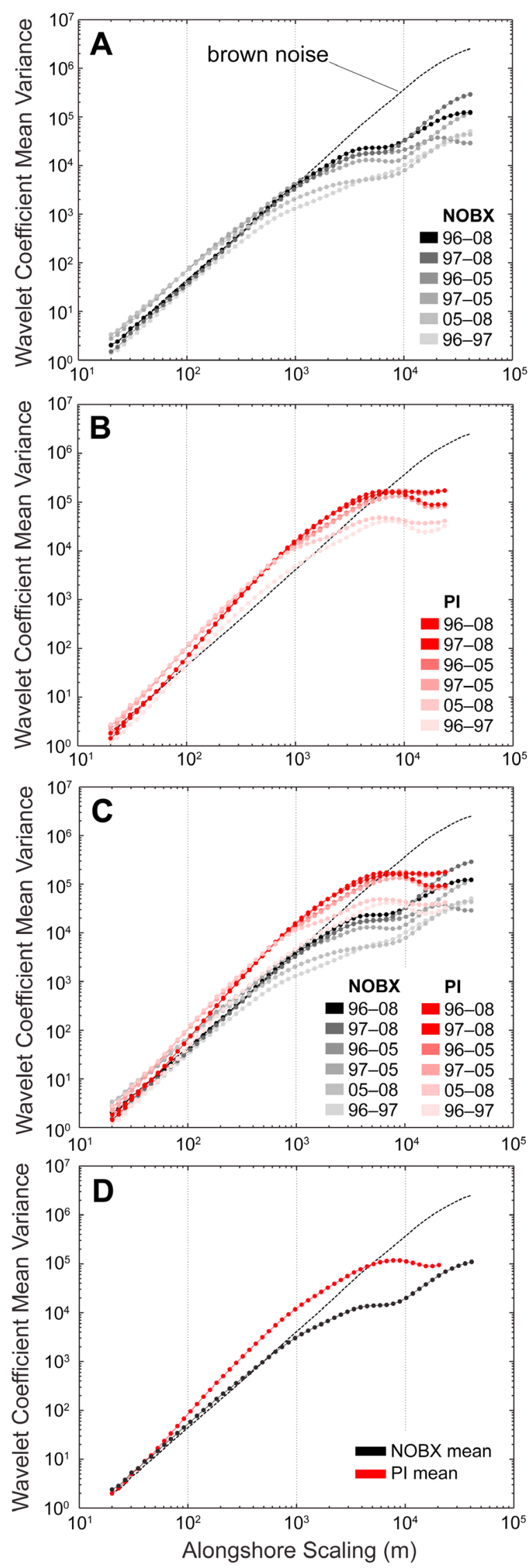

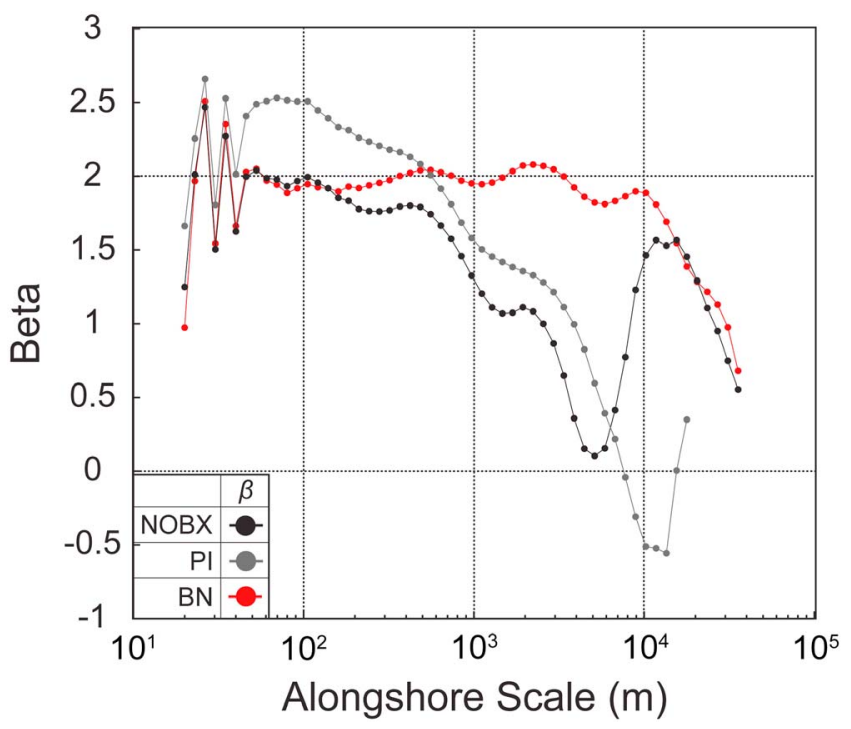

Figure 3. The $\beta$ values at sequential spatial scales for variance plots shown in Figure 2d. Brown noise (BN) has a characteristic $\beta \approx 2$.

(2) sample shoreline zones so that our regions of interest are in the signal interior and away from the edges, and (3) are less concerned with short-wavelength details than with longerwavelength patterns, the impact of edge effects in these data is greatly diminished. As an additional conservative step in the interest of focusing our attention on physically meaningful length scales, we present calculations only for alongshore scales equal to or smaller than half the full signal lengths and therefore all outside the associated COI.

\section{Results}

[16] Local maxima in the shoreline change power spectra highlight alongshore scales of particular significance. The local maxima for NOBX ( 4 km alongshore) and PI ( $\sim 8 \mathrm{~km})$ occur at spatial scales an order of magnitude smaller than the overall lengths of the measured shoreline change signal (Figures 2a-2c). We distinguish the first-occurring maximum from subsequent maxima because, at wavelet scales approaching the signal length (even if still within the COI), variance becomes increasingly an artifact of the wavelet processing technique and less representative of the data. Because a power spectrum for brown noise is fundamentally scale invariant, using the same processing technique on a stochastic brown noise signal (the integral of a white noise series) demonstrates that the meaningful maxima in the data are not wavelet artifacts (Figure 2).

Figure 2. Log-log plots relating mean shoreline change variance to alongshore scale, calculated using a continuous Haar wavelet transform, for (a) NOBX and (b) PI; (c) Figures 2a and $2 b$ superimposed. (d) The mean of the calculations shown in Figures 2a and 2b for NOBX (black) and PI (red). Dotted line shows the same variance calculations for a brown noise signal. 
[17] The approximate log-log linearity in the power spectra at alongshore scales up to $\sim 4-8 \mathrm{~km}$ reflects an extension of the result which previously prompted the suggestion that shoreline change variance might be described by a power law of the form $V=C x_{s}^{\beta}$, where $\beta$ is a measure of fractal roughness [Tebbens et al., 2002]. Figure 3 plots scale-to-scale $\beta$ values for the spectra plots in Figure 2d. Fluctuations in $\beta$ at scales $<50 \mathrm{~m}$ are probably a consequence of the Haar wavelet's poor resolution of high-frequency detail, but $\beta$ values for NOBX and PI nevertheless vary with scale. (Note that brown noise, by contrast, has a characteristic $\beta \approx 2$.) Though neither locality exhibits a scale-independent $\beta$, on average, $\beta$ values for PI consistently exceed those for NOBX up to the scales of the local maxima (Figures 2 and 3).

[18] Figure 2 also illustrates a temporal trend. Shoreline changes measured over longer temporal intervals ( $>3$ years) have greater variance magnitudes than those measured over shorter time periods (1-3 years), especially at larger spatial scales (Figures 2a-2c). Equally evident is the similarity in variance at smaller spatial scales $\left(<10^{3} \mathrm{~m}\right)$ across survey intervals and field locations. This combination of characteristics suggests a temporal control on the magnitude of change possible at a given spatial scale, which, in kind, would control the largest possible scale of mean variance. Assuming a minimum time scale greater than weeks that averages over ephemeral, storm-driven changes to beach position, which typically result in little net change [List et al., 2006; Brodie and McNinch, 2009], gradients in wave-driven alongshore sediment transport tend to inhibit runaway perturbations, whether by gradients in alongshore transport directly caused by shoreline curvature (described formally as diffusion of plan view morphology) or other negative morphodynamic feedbacks, and maintain a shoreline that is relatively straight in plan view [Ashton and Murray, 2006a; Lazarus and Murray, 2007]. Because the temporal scale of diffusion is proportional to the square of its length scale, diffusion changes smallest-scale features most rapidly, while large-scale changes require correspondingly more time to occur. We might therefore expect the local maxima for a longer temporal record of shoreline change to peak at an even larger spatial scale. The first local maximum in variance could occur at increasingly larger scales as the observation interval increases.

[19] Diffusional scaling from alongshore sediment transport processes provides rough estimates of the expected characteristic timescales of shoreline evolution $(t)$ as a function of alongshore spatial scale $(x)$,

$$
\tau=\frac{x^{2}}{\mu},
$$

where the shoreline diffusivity $(\mu)$ can be estimated from parameter values representative of the North Carolina Outer Banks:

$$
\mu=\frac{K}{D} T^{1 / 5} H^{12 / 5},
$$

using the empirical constant $K=0.34 \mathrm{~m}^{3 / 5} \mathrm{~s}^{-6 / 5}$, shoreface depth $D=10 \mathrm{~m}$, deep-water wave height $H=1.7 \mathrm{~m}$, and wave period $T=10 \mathrm{~s}$, assuming shore-parallel contours and shore-orthogonal incident waves [Ashton and Murray, 2006a, 2006b; Slott et al., 2006]. The computed $\mu$ of $0.19 \mathrm{~m}^{2} \mathrm{~s}^{-1}$ suggests that the characteristic time scale for diffusive change across spatial scales of $10 \mathrm{~km}$ is $\sim 16$ years; at $4 \mathrm{~km}$, this scale is approximately 3 years. However, approximate, these estimate appear to yield reasonable estimates, as the local maxima of our 2005-2008 shoreline comparisons (Figure 2) is $\sim 4 \mathrm{~km}$. Given that our longest lidar record is 12 years, this general scaling argument suggests that $10 \mathrm{~km}$ would represent an upper limit to the observed shoreline variability attributable to positive gradients in alongshore sediment transport.

[20] Consider a corollary: If we found shoreline change peaks at spatial scales significantly larger than the characteristic diffusive scale (or found that variance in shoreline change did not increase as time between surveys increased), we might conclude that those changes constitute evidence of some larger-scale structural influence dominating the system. Put another way, if there were refractive or bathymetric patterns on the coastline that were $\geq 10 \mathrm{~km}$ in scale, a related signal at that scale would be expected to appear in every comparison of shoreline position. Such dominant structural influences are certainly possible, but that particular pattern is not what we observe.

\section{Discussion}

\subsection{Cumulative Versus Transient Shoreline Change}

[21] Evidence of (1) high power in variance at large spatial scales for surveys spanning long durations, (2) comparatively lower (but still maximal) variance power at those large scales for surveys spanning short durations, and (3) the agreement among variance measurements at small spatial scales independent of survey duration and location suggests that the aggregation of shoreline position changes over longer time scales exerts a strong influence on large-scale spatial change. The shoreline experiences different physical processes across the range of spatial scales represented in our surveys (Figure 4). If each beach process were an equally dominant driver of change at its respective spatial scale, we might expect to see discrete peaks in spectral power at increasing orders of scale, but our results show no such punctuation or local maxima.

[22] Because lidar data are expensive to collect and store, temporal resolution for large, spatially extended surveys tends to be annual at best and therefore is poorly constrained for fine scales that require dense, spatially restricted sampling to resolve. If a morphodynamic rate is significantly faster than the time interval between surveys, we might expect shoreline features that are formed and erased on the order of days and weeks to have a generically similar quantitative signature in surveys recorded on the order of years (Figure 4). That said, variance related to small-scale features still appear in these data (Figure 2), and the apparent similarity of variances at spatial scales smaller than a few hundred meters is likely most indicative of temporal independence (shoreline change transience). If the greatest magnitudes of change, especially cumulative change, occurred at those small spatial scales, that predominance would be evident in the power spectra. But we find maxima in variance and notable differentiation in variance across both time and survey location only at scales greater than kilometers, scales at which most surf zone processes are exceeded and over 


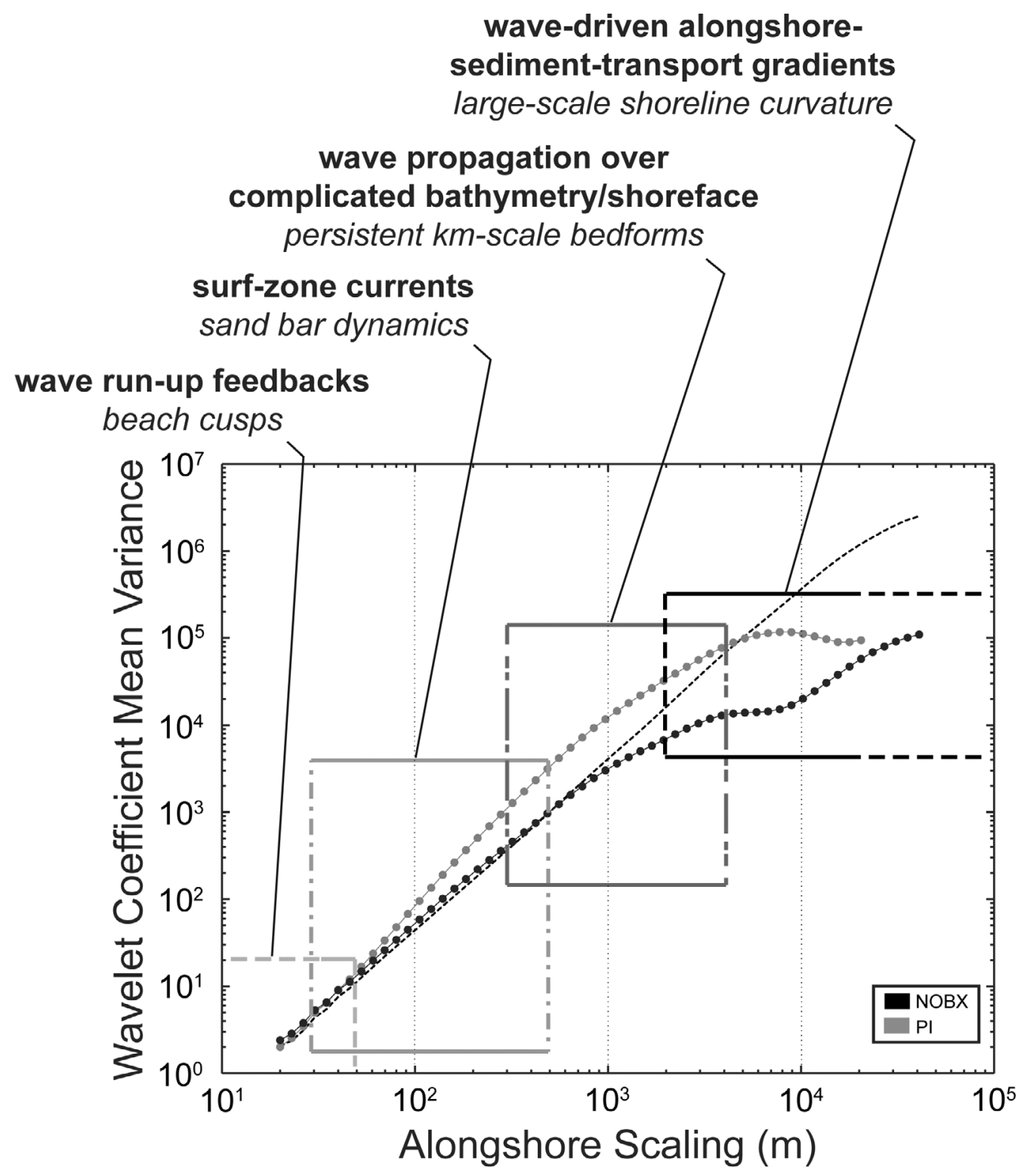

Figure 4. Different coastal morphodynamic processes indicated across the orders of spatial scales they typically affect, superimposed on the variance plots shown in Figure 2d (boxes after Cowell and Thom [1994] and List et al. [2006]).

which wave-driven alongshore sediment transport flux can act as a critical morphological agent (Figure 4).

[23] Fundamental aspects of shoreline shape diffusion driven by alongshore transport gradients might explain many observed characteristics of the local maxima [Lazarus and Murray, 2007], but diffusion alone probably does not explain the raw difference in variance magnitude between NOBX and PI. Pea Island exhibits higher magnitudes of shoreline variance across the larger spatial scales than NOBX, both overall (Figure 2d) and for each dated pair of surveys (Figure 2c); however, estimates of plan view shoreline diffusivity from local decadal wave climates [Ashton and Murray, 2006b] suggests that PI, based on wave angle climate, should reflect less, not more change than NOBX. Were positive shoreline diffusivity the sole agent of change [Lazarus and Murray,
2007], we would expect peak variances for PI to be smaller than NOBX.

[24] Continuous wavelet transforms of the 1996-2008 NOBX and PI shoreline change signals illustrate that the highest-magnitude variations in our data are not continuous throughout the signal but are, in fact, highly localized (Figure 5). The localized nature of certain large-scale excursions is informative, particularly to the extent that lithologic heterogeneities or bathymetric anomalies underlying the coastline (the "geologic framework") could effectively be reinforcing the amplitude of shoreline excursion in particular areas at particular scales [e.g., Schupp et al., 2006; Valvo et al., 2006], although not to such an extent that the diffusivity signal is swamped. 


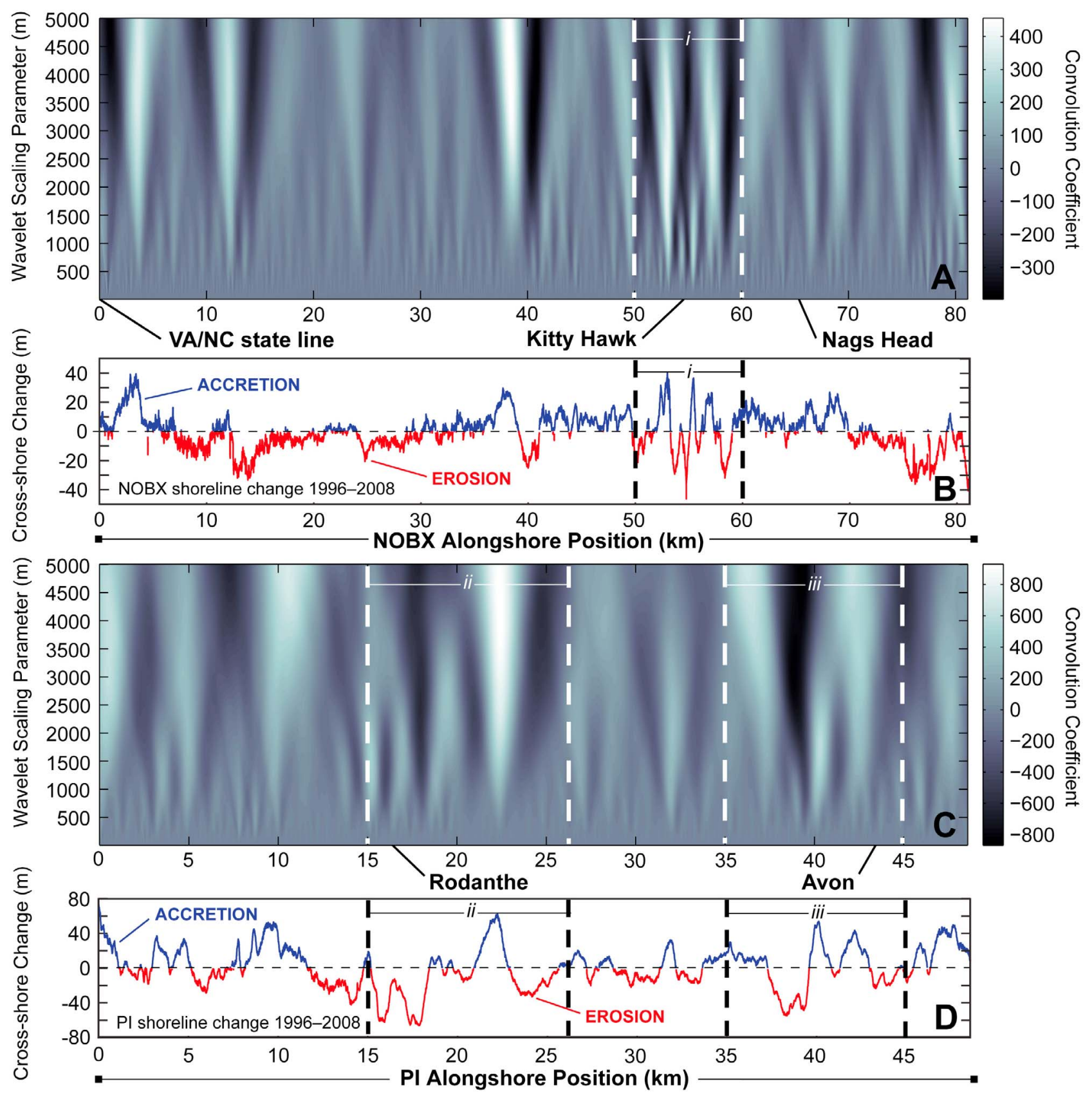

Figure 5. Full continuous wavelet transforms for (a) NOBX and (c) PI, with (b, d) the shoreline change measurements from which they are derived. Dotted lines indicate the approximate locations and alongshore spans of specific geologic framework features shown in Figure 1: the paleochannel and sandbar field near Kitty Hawk [after McNinch, 2004] (i) and Wimble (ii) and Kinnakeet Shoals (iii) near Rodanthe and Avon [after Riggs et al., 1995]. Certain sections of high variability in the shoreline change signal are spatially coincident with the demarcated zones.

[25] For NOBX and PI, bathymetric features arising from lithologic heterogeneities on their respective shorefaces may account for some of the large-scale changes in their shoreline positions. Along the length of NOBX, magnitudes of shoreline change are relatively small from the Virginia state line down to a bend in the coastline near the towns of Kitty Hawk and Nags Head (Figures 1 and 5). Proximal to Kitty Hawk, however, the shoreface intersects a relict, gravel-rich, fluvial paleochannel $\sim 6$-8 km wide [McNinch, 2004; Mallinson et al., 2005], and a substrate-related field of shore-oblique sandbars maintains itself in the nearshore zone [Schupp et al., 2006; Coco et al., 2007a, 2007b]. The bar field and paleochannel constitutes a bathymetric anomaly that alters crossshore and alongshore currents that could be the origin of pronounced, locally persistent shoreline fluctuations over alongshore scales of $10^{3} \mathrm{~m}$ (Figures 5a and 5b) [McNinch, 2004; Schupp et al., 2006]. Along PI, significant cross-shore changes occur over broad alongshore extents (Figures $5 \mathrm{c}$ 
Table 1. Akaike Information Criterion (AIC) Analysis

\begin{tabular}{|c|c|c|c|c|c|c|c|c|c|c|}
\hline Model & $\begin{array}{c}\text { Number of } \\
\text { Parameters }(\mathrm{K})\end{array}$ & $\mu$ (Scale) & $\begin{array}{l}\text { Standard } \\
\text { Error }\end{array}$ & $\sigma$ (Shape) & $\begin{array}{l}\text { Standard } \\
\text { Error }\end{array}$ & Log-Like & AIC & $\Delta \mathrm{AIC}$ & Weight & $\begin{array}{c}\text { Evidence } \\
\text { Ratio }\end{array}$ \\
\hline & & & & $N O B X$ & & & & & & \\
\hline Gamma & 2 ("scale," "shape”) & 0.31882 & 0.055870 & 9153.9 & 2997.3 & -337.65 & 679.29 & 0 & 0.487 & 1 \\
\hline Weibull & 2 ("scale," "shape") & 1288.4 & 484.74 & 0.43819 & 0.055090 & -337.94 & 679.89 & 0.60 & 0.361 & 1.3 \\
\hline Lognormal & 2 (mu, sigma) & 5.8373 & 0.43294 & 2.7722 & 0.31189 & -338.81 & 681.62 & 2.33 & 0.151 & 3.2 \\
\hline Generalized Pareto $^{a}$ & $3(\mathrm{k}$, sigma, theta $)$ & 3.0102 & 0.72698 & 77.907 & 44.881 & -342.99 & 691.98 & 12.96 & $7.30 \mathrm{E}-04$ & - \\
\hline Exponential & $1(\mathrm{mu})$ & 2918.4 & 455.78 & - & - & -368.13 & 738.26 & 58.97 & 0 & - \\
\hline \multirow[t]{2}{*}{ Logistic } & $2(\mathrm{mu}$, sigma $)$ & 2053.2 & 594.90 & 2219.4 & 305.27 & -399.44 & 802.89 & 123.60 & 0 & - \\
\hline & & & & $P I$ & & & & & & \\
\hline Gamma & 2 ("scale," "shape") & 0.24539 & 0.042140 & 63223 & 22697 & -383.62 & 771.24 & 0 & 0.469 & 1 \\
\hline Weibull & 2 ("scale," "shape") & 4358.1 & 2028.45 & 0.35423 & 0.044427 & -383.87 & 771.75 & 0.51 & 0.364 & 1.4 \\
\hline Lognormal & 2 (mu, sigma) & 6.7463 & 0.53372 & 3.4174 & 0.384497 & -384.66 & 773.32 & 2.08 & 0.166 & 2.8 \\
\hline Generalized Pareto $^{a}$ & $3(\mathrm{k}$, sigma, theta $)$ & 4.3724 & 0.93037 & 62.100 & 40.422 & -389.55 & 785.09 & 13.85 & 0 & - \\
\hline Exponential & $1(\mathrm{mu})$ & 15514 & 2422.9 & - & - & -436.63 & 875.26 & 104.02 & 0 & - \\
\hline Logistic & $2(\mathrm{mu}$, sigma $)$ & 9699.8 & 3249.5 & 12413 & 1750.1 & -471.52 & 947.04 & 175.80 & 0 & - \\
\hline
\end{tabular}

an the generalized Pareto models, threshold parameter "theta" $=1.5$ and has no associated standard error.

and 5d), with two areas of focused erosion approximately onshore of hard bottom shoals that trend shore-oblique to Rodanthe and Avon (Figure 1) [Riggs et al., 1995] and are coincident with island segments characterized by gravelly, coarse-grained paleoinlet complexes [Mallinson et al., 2010]. Preliminary findings from new radar-based data acquisition techniques [McNinch, 2007] indicate other shore-oblique bar complexes dispersed along PI morphologically similar to those identified to the north (J. McNinch, personal communication, 2009). These geologic framework features, even if loosely spatially correlated with zones of shoreline change, could at least affect higher magnitudes of change and perhaps resist the homogenizing effects of alongshore diffusional smoothing [e.g., Valvo et al., 2006; Lazarus and Murray, 2011]; a resulting power spectrum would show higher variances at spatial scales comparable to those of the anomalies.

\subsection{Interpretation of Power Laws}

[26] Invoking the role of geologic framework does not herald the argument that "every beach is different," the scaling relationships evident in our measurements of beach change indicate a common, if complex interconnectivity within the coastal system. Persistence of an apparent log-log linearity in shoreline change variance across such a broad range of spatial scales raises an intriguing point regarding power laws and their interpretation with respect to the underlying processes responsible for change. Because our results do not indicate the dominance of any one of the processes across the scales included in the power spectra (Figure 4), we submit that an apparent power law is not necessarily the statistical signature of a system with a single governing physical process or set of interactions. We emphasize that whenever a power law can be applied to a natural phenomenon, researchers should examine its mechanistic implications with care [Murray, 2007; Solow, 2005].

[27] Moreover, the approximate linearity of data in doublelogarithmic plots does not prove definitively that a power law is their only, or even best, descriptor. For example, a lognormal distribution and a power law distribution can appear strikingly similar over a large interval [Sornette, 2006]. Statistical measures of distribution model uncertainty, such as the Akaike information criterion (AIC), are gaining application in ecology fields because the comparative indices such criteria provide are better suited for parameter estimation and model selection than traditional techniques of null hypothesis testing [Anderson et al., 2000; Burnham and Anderson, 2002]. The AIC [Akaike, 1973] relates the maximum-likelihood estimation for a given distribution to the distribution's Kullback-Leibler information, which is a measure of how well a model approximates the data [Burnham and Anderson, 2001, 2002], and is defined as

$$
A I C=2 K-2(\text { log-likelihood }),
$$

where $K$ is the number of estimated parameters in a distribution.

[28] To frame our data with the AIC [e.g., Burnham and Anderson, 2002; Mazerolle, 2004], we apply the distributionfitting tool in Matlab $R 2009 b$ to the variance spectra in Figure 2d (out to $5120 \mathrm{~m}$ ) to generate the log likelihood and parameter estimates for a variety of distribution models (Table 1). Because the AIC value for a given model $i$ only has meaning when compared to AIC values for other models, model comparisons hinge on two metrics: the difference from the minimum AIC for the models under consideration ( $\triangle A I C)$, and the Akaike weight, which normalizes the differences, defined as

$$
\text { weight }_{i}=\exp \left(-\Delta A I C_{i} / 2\right) / \sum_{m=1}^{M} \exp \left(-\Delta A I C_{m} / 2\right),
$$

where $\mathrm{M}$ is the number of models being compared. The weight reflects the probability that model $i$ is the best of the models under consideration. The evidence ratio, which compares the weights, indicates the degree to which one model is better than another [Mazerolle, 2004].

[29] Generally, $\triangle A I C<2$ suggests strong support for a model, $3<\triangle A I C<7$ suggests weak support, and $\triangle A I C>$ 10 is evidence that a model is highly unlikely match for the data. In our analysis of six distributions, Gamma, Weibull, and lognormal distributions rank highest for both NOBX and PI (Table 1), but the selection criteria do not indicate an overwhelming choice among these models. Not only are the standard errors around many of the parameter estimates high, but the top-scoring Gamma models for NOBX and PI are still no better than $50 \%$ likely to be the best of the distributions compared. (The evidence ratios for NOBX, for 
example, show that the Gamma model is 3.2 times better than the lognormal model, but only 1.3 times better than a Weibull.) A generalized Pareto distribution (a power law form) ranks fourth against the others (Table 1), meaning a power law may actually be a poor descriptor of these data over the three spatial orders of magnitude we include in the AIC analysis.

[30] Aside from the ambiguity regarding which statistical distribution best captures shoreline change variance, a dynamical explanation for why these data demonstrate such coherent trends at all is elusive. Although the exponential relationships demonstrable in natural shoreline change could suggest a dominant process or form of interaction (as in the archetypical example of turbulence), particularly over spatial scales less than kilometers, a host of known processes and dynamic interactions affect shoreline behavior over those different spatial scales (Figure 4). The magnitudes of variance we observe may reflect in part the relative influence of geologic framework on patterns of shoreline change, but the marked increase in maximum mean variance with time over alongshore scales on the order of kilometers suggests the morphodynamic predominance of diffusion-type processes there. Given that diffusion, more than other processes, can affect the shoreline at all scales (regardless of whether it is the dominant shoreline change process at a particular scale), a possible hypothesis for the nonstationary variance observed over so many scales is that extended shoreline change records are analogous to, if not another manifestation of, "signal shredding," the erasure or effective dampening of small-scale perturbations by changes at large scale. This phenomenon has been suggested in the evolution of other closely related sediment transport systems [Jerolmack and Paola, 2010], where internal system dynamics can erase periodic forcing at temporal scales smaller than those of the characteristic morphologic system. The results here suggest a spatial analogy, that the signal of forcing and behavior over sufficiently small alongshore extents is not retained in the "memory" of longerterm change, which manifests at larger spatial scales.

\section{Conclusions}

[31] Why shoreline changes driven by so many different processes, each operating over a relatively restricted range of scales, nevertheless exhibit a consistent trend across a wider range of scales in a power spectrum remains a scintillating question awaiting continued research. Just as satellite imagery such as MODIS with high spatiotemporal resolution has enabled finer observation of phenological shifts (such as changes in where and when deciduous trees leaf out) at subcontinental scales [e.g., Zhang et al., 2006], perhaps the next stage of satellite technology will enable observations of geomorphic landscape change up to regional scales with time-averaged resolution. Measuring gradual but persistent, cumulative coastal change (and subsequently managing those changes) may require a different set of strategies than those designed for the kinds of large but ephemeral changes that accompany storms [e.g., Holman and Stanley, 2007; McNinch, 2007].

[32] In summary, we find that a power law can describe the mean variance of shoreline change at alongshore scales from tens of meters up to $\sim 4-8 \mathrm{~km}$, although other exponential distributions statistically provide a better fit. Even applying a power law does not necessarily reveal a scalefree process, and more insights into shoreline change processes may in fact come from where the data depart from an apparent power law relationship. In addition, the maximum mean variance of shoreline change, and the scale at which that maximum occurs, both increase as surveys span longer time scales in a manner consistent with diffusion, suggesting (1) a potential temporal control on the magnitude of change possible at a given spatial scale and (2) that cumulative shoreline change is an important component of large-scale shifts in shoreline position. The results here, therefore, may be considered to provide a unique quantitative measure and demonstration of large-scale coastal behavior [de Vriend et al., 1993].

[33] Acknowledgments. Our thanks to the NSF (grant EAR-0444792) for funding this research; to the Joint Airborne Lidar Bathymetry Technical Center for Expertise (JALBTCX) and the Gulf of Maine Research Institute for their technical and infrastructural support; to P. Haff, J. McNinch, D. McNamara, P. Limber, and A. Payson; and to our three reviewers for their comments.

\section{References}

Akaike, H. (1973), Information theory as an extension of the maximum likelihood principle, in Second International Symposium on Information Theory, edited by B. N. Petrov and F. Csaki, pp. 267-281, Akad. Kiado, Budapest.

Anderson, D. R., K. P. Burnham, and W. L. Thompson (2000), Null hypothesis testing: Problems, prevalence, and an alternative, J. Wildl. Manage., 64, 912-923, doi:10.2307/3803199.

Ashton, A. D., and A. B. Murray (2006a), High-angle wave instability and emergent shoreline shapes: 1 . Modeling of sand waves, flying spits, and capes, J. Geophys. Res., 111, F04011, doi:10.1029/2005JF000422.

Ashton, A. D., and A. B. Murray (2006b), High-angle wave instability and emergent shoreline shapes: 2 . Wave climate analysis and comparisons to nature, J. Geophys. Res., 111, F04012, doi:10.1029/2005JF000423.

Ashton, A., A. B. Murray, and O. Arnoult (2001), Formation of coastline features by large-scale instabilities induced by high-angle waves, Nature, 414, 296-300, doi:10.1038/35104541.

Bak, P. (1996), How Nature Works: The Science of Self-Organized Criticality, Springer, New York.

Bak, P., K. Christensen, L. Danon, and T. Scanlon (2002), Unified scaling law for earthquakes, Phys. Rev. Lett., 88(17), 178501, doi:10.1103/ PhysRevLett.88.178501.

Brodie, K. L., and J. E. McNinch (2009), Measuring bathymetry, runup, and beach volume change during storms: New methodology quantifies substantial changes in cross-shore sediment flux, Eos Trans. $A G U, 90(52)$, Fall Meet. Suppl., Abstract NH11A-1111.

Burnham, K. P., and D. R. Anderson (2001), Kullback-Leibler information as a basis for strong inference in ecological studies, Wildl. Res., 28, 111-119, doi:10.1071/WR99107.

Burnham, K. P., and D. R. Anderson (2002), Model Selection and Multimodel Inference, Springer, New York.

Coastal Services Center (2010), Digital coast, NOAA, Silver Spring, Md. (Available at http://www.csc.noaa.gov/digitalcoast/data/coastallidar/ details.html.)

Coco, G., T. K. Burnet, B. T. Werner, and S. Elgar (2003), Test of selforganization in beach cusp formation, J. Geophys. Res., 108(C3), 3101, doi:10.1029/2002JC001496.

Coco, G., A. B. Murray, and M. O. Green (2007a), Sorted bed forms as self-organized patterns: 1. Model development, J. Geophys. Res., 112, F03015, doi:10.1029/2006JF000665.

Coco, G., A. B. Murray, M. O. Green, E. R. Thieler, and T. M. Hume (2007b), Sorted bed forms as self-organized patterns: 2. Complex forcing scenarios, J. Geophys. Res., 112, F03016, doi:10.1029/2006JF000666.

Cowell, P. J., and B. G. Thom (1994), Morphodynamics of coastal evolution, in Coastal Evolution: Late Quaternary Shoreline Morphodynamics, edited by R. W. G. Carter and C. D. Woodroffe, pp. 33-86, Cambridge Univ. Press, Cambridge, U. K.

de Vriend, H. J., M. Capobianco, T. Chesher, H. E. de Swart, B. Latteux and M. J. F. Stive (1993), Approaches to long-term modelling of coastal 
morphology: A review, Coastal Eng., 21, 225-269, doi:10.1016/03783839(93)90051-9.

Dolan, R., and J. C. Ferm (1968), Crescentic landforms along the Atlantic Coast of the United States, Science, 159, 627-629, doi:10.1126/science. 159.3815.627.

Fenster, M. R., and R. Dolan (1996), Assessing the impact of tidal inlets on adjacent barrier island shorelines, J. Coastal Res., 12, 294-310.

Frette, V., K. Christensen, A. Malthe-Sørenssen, J. Feder, T. Jøssang, and P. Meakin (1996), Avalanche dynamics in a pile of rice, Nature, 379, 49-52, doi:10.1038/379049a0.

Gunawardena, Y., S. Ilic, H. N. Southgate, and H. Pinkerton (2008), Analysis of the spatio-temporal behavior of beach morphology at Duck using fractal methods, Mar. Geol., 252, 38-49, doi:10.1016/j.margeo. 2008.03.013.

Holman, R. A., and J. Stanley (2007), The history and technical capabilities of Argus, Coastal Eng., 54, 477-491, doi:10.1016/j.coastaleng.2007. 01.003 .

Hubbard, B. B. (1996), The World According to Wavelets: The Story of a Mathematical Technique in the Making, A. K. Peters, Wellesley, Mass.

Jerolmack, D. J., and C. Paola (2007), Complexity in a cellular model of river avulsion, Geomorphology, 91, 259-270, doi:10.1016/j.geomorph. 2007.04.022.

Jerolmack, D. J., and C. Paola (2010), Shredding of environmental signals by sediment transport, Geophys. Res. Lett., 37, L19401, doi:10.1029/ 2010GL044638.

Lazarus, E. D., and A. B. Murray (2007), Process signatures in regional patterns of shoreline change on annual to decadal time scales, Geophys. Res. Lett., 34, L19402, doi:10.1029/2007GL031047.

Lazarus, E. D., and A. B. Murray (2011), An integrated hypothesis for regional patterns of shoreline change along the northern North Carolina Outer Banks, USA, Mar. Geol., 281, 85-90, doi:10.1016/j.margeo. 2011.02.002.

List, J. H., and A. D. Ashton (2007), A circulation modeling approach for evaluating the conditions for shoreline instabilities, in Proceedings of Coastal Sediments '07, edited by N. C. Kraus and J. D. Rosati, pp. 327-340, doi:10.1061/40926(239)25, Am. Soc. of Civ. Eng., Reston, Va.

List, J. H., A. S. Farris, and C. Sullivan (2003), Large-scale response of foreshore slope to storm events, in Proceedings of Coastal Sediments '03 [CD ROM], edited by R. A. Davis, A. H. Sallenger, and P. Howd, World Sci., Corpus Christi, Tex.

List, J. H., A. Farris, and C. Sullivan (2006), Reversing storm hotspots on sandy beaches: Spatial and temporal characteristics, Mar. Geol., 226, 261-279, doi:10.1016/j.margeo.2005.10.003.

Madsen, A. J., and N. G. Plant (2001), Intertidal beach slope predictions compared to field data, Mar. Geol., 173, 121-139, doi:10.1016/S00253227(00)00168-7.

Mallinson, D., S. Riggs, E. R. Thieler, S. Culver, K. Farrell, D. S. Foster, D. R. Corbett, B. Horton, and J. F. Wehmiller (2005), Late Neogene and Quaternary evolution of the northern Albemarle embayment (MidAtlantic continental margin, USA), Mar. Geol., 217, 97-117, doi:10.1016/ j.margeo.2005.02.030.

Mallinson, D. J., C. W. Smith, S. J. Culver, S. R. Riggs, and D. Ames (2010), Geological characteristics and spatial distribution of paleo-inlet channels beneath the Outer Banks barrier islands, North Carolina, USA, Estuarine Coastal Shelf Sci., 88, 175-189, doi:10.1016/j.ecss. 2010.03.024.

Mandelbrot, B. (1967), How long is the coast of Britain? Statistical selfsimilarity and fractional dimension, Science, 156, 636-638, doi:10.1126/ science.156.3775.636.

Mazerolle, M. J. (2004), Appendix 1: Making sense out of Akaike's information criterion (AIC): Its use and interpretation in model selection and inference from ecological data, in Mouvements et Reproduction des Amphibiens en Tourbières Perturbées, Ph.D. thesis, pp. 174-190, Univ. Laval, Quebec, Que., Canada. (Available at http://archimede.bibl.ulaval. ca/archimede/fichiers/21842/apa.html.)
McNinch, J. E. (2004), Geologic control in the nearshore: Shore-oblique sandbars and shoreline erosional hotspots, Mid-Atlantic Bight, USA, Mar. Geol., 211, 121-141, doi:10.1016/j.margeo.2004.07.006.

McNinch, J. E. (2007), Bar and swash imaging radar (BASIR): A mobile $\mathrm{X}$-band radar designed for mapping nearshore sand bars and swashdefined shorelines over large distances, J. Coastal Res., 23, 59-74.

Murray, A. B. (2007), Two paradigms in landscape dynamics: Self-similar processes and emergence, in Nonlinear Dynamics in Geosciences, edited by A. A. Tsonis and J. B. Elsner, Earth Environ. Sci., 1, 17-35, doi:10.1007/ 978-00-387-34918-3 2.

Nievergelt, Y. (1999), Wavelets Made Easy, Birkhäuser, Boston, Mass.

Pelletier, J. D. (1999), Self-organization and scaling relationships of evolving river networks, J. Geophys. Res., 104, 7359-7375, doi:10.1029/ 1998JB900110.

Riggs, S. R., W. J. Cleary, and S. W. Snyder (1995), Influence of inherited geologic framework on barrier shoreface morphology and dynamics, Mar. Geol., 126, 213-234, doi:10.1016/0025-3227(95)00079-E.

Ruessink, B. G., G. Coco, R. Ranasinghe, and I. L. Turner (2007), Coupled and noncoupled behavior of three-dimensional morphological patterns in a double sandbar system, J. Geophys. Res., 112, C07002, doi:10.1029/ 2006JC003799.

Schupp, C. A., J. E. McNinch, and J. H. List (2006), Nearshore shoreoblique bars, gravel outcrops, and their correlation to shoreline change, Mar. Geol., 233, 63-79, doi:10.1016/j.margeo.2006.08.007.

Slott, J. M., A. B. Murray, A. D. Ashton, and T. J. Crowley (2006), Coastline responses to changing storm patterns, Geophys. Res. Lett., 33, L18404, doi:10.1029/2006GL027445.

Solow, A. (2005), Power laws without complexity, Ecol. Lett., 8, 361-363, doi:10.1111/j.1461-0248.2005.00738.x.

Sornette, D. (2006), Critical Phenomena in Natural Sciences, Springer, New York.

Southgate, H. N., and I. Möller (2000), Fractal properties of coastal profile evolution at Duck, North Carolina, J. Geophys. Res., 105, 11,489-11,507, doi:10.1029/2000JC900021.

Tebbens, S. F., S. M. Burroughs, and E. E. Nelson (2002), Wavelet analysis of shoreline change on the Outer Banks of North Carolina: An example of complexity in the marine sciences, Proc. Natl. Acad. Sci. U. S. A., 99, suppl. 1, 2554-2560.

Valvo, L. M., A. B. Murray, and A. Ashton (2006), How does underlying geology affect coastline change? An initial modeling investigation, J. Geophys. Res., 111, F02025, doi:10.1029/2005JF000340.

Werner, B. T., and T. M. Fink (1993), Beach cusps as self-organized patterns, Science, 260, 968-971, doi:10.1126/science.260.5110.968.

Zhang, X., M. A. Friedl, and C. B. Schaaf (2006), Global vegetation phenology from Moderate Resolution Imaging Spectroradiometer (MODIS): Evaluation of global patterns and comparison with in situ measurements, J. Geophys. Res., 111, G04017, doi:10.1029/2006JG000217.

A. Ashton, Department of Geology and Geophysics, Woods Hole Oceanographic Institution, 360 Woods Hole Rd., MS 22, Woods Hole, MA 02543, USA.

S. Burroughs, Department of Physics, University of Tampa, 401 West Kennedy Blvd., Tampa, FL 33606, USA

E. Lazarus, Senator George J. Mitchell Center for Environmental and Watershed Research, University of Maine, 5710 Norman Smith Hall, Orono, ME 04469-5710, USA. (eli.lazarus@maine.edu)

A. B. Murray, Division of Earth and Ocean Sciences, Nicholas School of the Environment, Center for Nonlinear and Complex Systems, Duke University, 103 Old Chemistry Bldg., Box 90227, Durham, NC 27708, USA.

S. Tebbens, Department of Physics, Wright State University, 3640 Colonel Glenn Highway, Dayton, OH 45436, USA. 